\title{
A Solution to Economic Dispatch Problem Using Hybrid Particle Chemical Reaction Optimization (HP-CRO) ALGORITHM
}

\author{
Maisam Abbas* \\ MSc. Scholar Department of Electrical Engineering \\ University of Engineering and Technology Taxila \\ Pakistan \\ maisamee56@gmail.com \\ Aftab Ahmad \\ Chairman Department of Electrical Engineering \\ University of Engineering and Technology, Taxila \\ Pakistan \\ aftab.ahmad@uettaxila.edu.pk \\ Yasir Kamal \\ Department of Management Sciences \\ Institute of Management Sciences, Peshawar \\ Pakistan \\ yasir.kamal@imsciences.edu.pk \\ Hamayoon Shah \\ Department of Management Sciences \\ Institute of Management Sciences, Peshawar \\ Pakistan \\ shahhamayun@gmail.com
}

*Corresponding Author email: maisamee56@gmail.com 


\section{A B S T R A C T}

The electrical control request is on stagger due to constant growth in entreaty since manufacturing firms besides ménage. Consequently augmented plus price operational power cohort is the prerequisite of the era. In power classification process plus scheduling the Economic Dispatch (ED) tricky is prevailing and noteworthy some. The ED problematic of several standards is disentangled through consequently sundry conventional and meta-heuristics aggrandizement skills. Now the triumphed investigation exertion, a unique plus innovative aggrandizement way, Chemical Reaction Optimization (CRO) mongrelised thru Particle Swarm Optimization (PSO) system is recommended aimed at the explanation of ED problematic. Generating unit power limits, load fulfillment and prohibited operating zones remain painstaking by way of guarded on behalf of diverse IEEE customary ED muddles. The non-convex economic dispatch hitch is coded at Hybrid Particle Chemical Reaction Optimization (HP-CRO) contrivance then selected the MATLAB environment intended for 50 prosecutions, 50 search agents and 1000 iterations. The offered scheme stands smeared proceeding a number of IEEE usual trial structures counting six, fifteen plus forty engendering parts. The displayed upshots stay coordinated per quantified wont declared hip the articles aimed at directly above trial structures. The costs obtained commencing wished-for modus operandi bounce a superiority toward individuals gained after new practise on one occasion price opinion.

Keywords: Power System Planning, Hybrid Particle Chemical Reaction Optimization, Economic Dispatch, Valve Point Loading Effect, Transmission Loss

\section{R E S E A R C H H I G H L I G H T S}

1. The economic dispatch problem is solved with nature inspired optimization algorithm, hybrid particle chemical reaction optimization (HP-CRO) algorithm on MATLAB .

2. The ED problem is solved for six, fifteen and forty entities IEEE customary quiz organisms with load demand of 1,263 MW, $2630 \mathrm{MW}$ and 10,500 MW respectively.

3. The optimal value of fuel cost and transmission losses for 6,15 and 40 units test systems were recoreded as $15448.69782 \$ / \mathrm{hr}$ with $13.03514122 \mathrm{MW}, 32550.70502 \$ / \mathrm{hr}$ with 27.64292219 MW and 135623.0431 \$/hr with 974.7681427 MW respectively.

\section{Research Objectives}

\section{Aim}

To appliance Hybrid Particle Chemical Reaction Optimization (HP-CRO) principle aimed at explanation of fiscal (economic) report (dispatch) trick through slightest price number.

\section{Objective}

1. To analysis the texts on curved and quincunx economic (fiscal) dispatch (report) questions.

2. To sightsee the HP-CRO process. 
3. To appliance HP-CRO procedure in MATLAB programming aimed at the explanation of economic dispatch delinquent.

4. To assessed besides corroborate the HP-CRO set of rules on IEEE customary hitches of six, fifteen and forty entities scheme accessible in collected works.

5. To associate outcomes of HP-CRO set of rules via supplementary meta-haruspex.

\section{Methodology}

The economic dispatch problem is solved optimzal fuel cost (equ.1) with the help of nonconvex quatratic fuel cost curve equation (equ.2) and transmission losses (equ.3) incured in the transmission lines. The problem is solved for power limits(equ.4), power balance(equ.5) and prohiboted operating zones (equ.6) constraints. This problem is solved with so many optimization algorithm with various constraints and every technique provide optimal results when compared with previous optimization algorithms mentioned in the literature such as Genetic Algorithm(1), Particle Swarm Optimization(2), Modified Flower Pollination Algorithm(3) etc. In prevailed work the ED problem is solved with cantankerous particle (unit) chemical (substance) reaction (riposte) boost set of rules as discussed in (4). The hybrid particle chemical reaction optimization algorithm is subsidization of PSO(5) (equ.7 \& 8) and CRO (6) (equ.9 \& 10) algorithm with capabilities of global and local search respectively is an effective technique and is applied for solution of various optimization problems.

$$
\begin{aligned}
& F_{t}=\sum_{i=1}^{N} F_{i}\left(P o_{i}\right) \\
& \text { Total } F_{i}\left(P o_{i}\right)=c_{i} P o_{i}^{2}+b_{i} P o_{i}+a_{i}+\left|e_{i}+\operatorname{sine}\left(f_{i} \times\left(P_{i, m i n}-P o_{i}\right)\right)\right| \\
& P o_{\text {Loss }}=\sum_{i=1}^{n} \sum_{j=1}^{n} P o_{i} \text { Bmat }_{i, j} P o_{j}+\sum_{i=1}^{n} \text { Bmat }_{i 0} P_{i}+\text { Bmat }_{00} \\
& P o_{i, m i n} \leq P o_{i} \leq P o_{i, m a x} \\
& \sum_{i=1}^{n} P o_{i}=P o_{D}+P o_{\text {Loss }} \\
& P o_{i(2)} \leq P o_{i} \leq P o_{i(3)} \\
& V_{i}^{k+1}=\omega V_{i}^{k}+c_{1} r a n d_{1}\left(P_{b e s t}^{k}-X_{i}^{k}\right)+c_{2} \text { rand }_{2}\left(\text { Gbest }^{k}-X_{i}^{k}\right) \\
& X_{i}^{k+1}=X_{i}^{k}+V_{i}^{k+1} \\
& P E_{w}+K E_{w} \geq P E_{w^{\prime}} \\
& P E_{w 1}+P E_{w 2}+K E_{w 1}+K E_{w 2} \geq P E_{w^{\prime} 1}+P E_{w^{\prime} 2}
\end{aligned}
$$

\section{Results}

The optimal results happening in form of fuel cost in $\$ / \mathrm{hr}$ and tranmission losses in MW for all the three cases of 6,15 and 40 unit standard test system using Hybrid Particle Chemical 
Reaction Optimization Algorithm in MATLAB environment are $15448.69782 \$ / \mathrm{hr}$ with 13.03514122 mega watt for total load demand of 1263 mega watt, 32550.70502 \$/hr with 27.64292219 mega watt for total capacity ultimatum of 2,630 mega watt in addition to 135623.0431 \$/hr with 974.7681427 mega watt for capacity claim of 10,500 mega watt respectively.

\section{Findings}

After application of HP-CRO algorithm for the explanation of E (economic) D (disatch) problem with non-convex nature of curve it is find out that proposed algorithm out classed the other optimization algorithms in all the three cases. The optimal cost for 6,15 and 40 units test system are then compared with other optimization algorithms like Artificial Immune System(7), Invasive Weed Optimization(8), Rooted Tree Optimization(9) and so on. The outcomes found over HP-CRO procedure remain distant improved than those attained over above stated algorithms for the same system of units.

\section{References}

1. 1. Walters DC, Sheble GB. Genetic algorithm solution of economic dispatch with valve point loading. IEEE Trans Power Syst. 1993; 8(3): 1325-32.

2. 2. Park JB, Lee KS, Shin JR, Lee KY. A particle swarm optimization for economic dispatch with nonsmooth cost functions. IEEE Trans Power Syst. 2005; 20(1): 34-42.

3. 3. Dubey HM, Pandit M, Panigrahi BK. A Biologically Inspired Modified Flower Pollination Algorithm for Solving Economic Dispatch Problems in Modern Power Systems. Cognit Comput [Internet]. 2015; 7(5): 594-608. Available from: http://dx.doi.org/10.1007/s12559-015-9324-1

4. 4. Nguyen TT, Li Z, Zhang S, Truong TK. A hybrid algorithm based on particle swarm and chemical reaction optimization. Expert Syst Appl [Internet]. 2014; 41(5): 2134-43. Available from: http://dx.doi.org/10.1016/j.eswa.2013.09.012

5. 5. Kennedy J, Eberhart R. Particle swarm optimization. In: in Proc IEEE Int Conf Neural Networks (ICNN'95), vol IV, Perth, Australia. 1995. p. 1942-8.

6. 6. Lam AYS, Li VOK. Chemical-reaction-inspired metaheuristic for optimization. IEEE Trans Evol Comput. 2010; 14(3): 381-99.

7. 7. Basu M. Artificial immune system for dynamic economic dispatch. Int J Electr Power Energy Syst [Internet]. 2011; 33(1): 131-6. Available from: http://dx.doi.org/10.1016/j.ijepes.2010.06.019

8. 8. Jayabarathi T, Yazdani A, Ramesh V. Application of the invasive weed optimization algorithm to economic dispatch problems. Front Energy. 2012; 6(3): 255-9.

9. 9. Labbi $Y$, Attous D Ben, Gabbar HA, Mahdad B, Zidan A. A new rooted tree optimization algorithm for economic dispatch with valve-point effect. Int J Electr Power Energy Syst [Internet]. 2016; 79: 298-311. Available from: http://dx.doi.org/10.1016/j.ijepes.2016.01.028 


\section{Author's Biography}

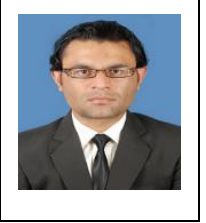

Maisam Abbas is M.Sc scholar in the department of Electrical Engineering, University of Engineering and Technology, Taxila, Pakistan. He completed his Master of Business Administration from Institute of Management Sciences, Peshawar, Pakistan in the year 2017. He completed his Bachelor of Engineering in Electrical from NED University of Engineering and Technology, Karachi, Pakistan in the year 2012. His research interest includes power system analysis, economic dispatch, nature inspired optimization.

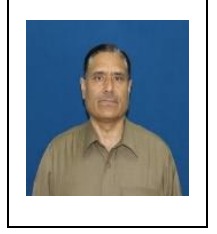

Dr. Aftab Ahmad is currently offering his services as a professor and chairman in the department of electrical engineering, University of Engineering and Technology, Taxila, Pakistan. He completed his PhD degree from University of Engineering and Technology, Taxila, Pakistan. He served in various position in the University of Engineering and Technology with approximately 25 years of experience. His research interest includes unit commitment, economic dispatch, engineering optimization, research methodology and application of nature inspired optimization techniques for solution of various electrical power system planning and operation problems

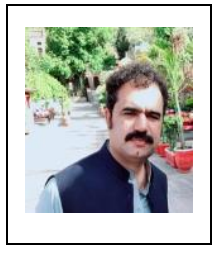

Dr. Yasir Kamal is an Associate professor at Institute of Management Sciences, Peshwar, Pakistan. He completed his PhD degree from ZABIST Islamabad. His research interest includes financial analysis, energy economics, statistical data analysis and planning for government policies.

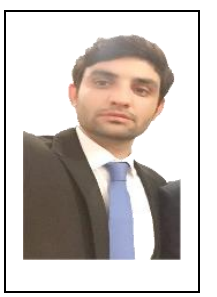

Hamayoon Shah is a research consultant working with the Deutsche Gesellschaft für Internationale Zusammenarbeit (GIZ) in the Elementary and Secondary Education sector of Pakistan. He graduated from the Institute of Management Sciences Peshawar, with a master's degree in finance in 2018. He has worked on different research projects with multiple international organizations like UNDP, British Council, and SUBAI Pakistan. 